Luxembourg Income Study

Working Paper No. 252

CHANGING INCOME INEQUALITY IN OECD COUNTRIES: UPDATED RESULTS

FROM THE LUXEMBOURG INCOME STUDY (LIS)

Timothy M. Smeeding

with assistance from Andrzej Grodner

March 2000 


\title{
Changing Income Inequality in OECD Countries: Updated Results from the Luxembourg Income Study (LIS)
}

\author{
Timothy M. Smeeding ${ }^{1}$ with assistance from Andrzej Grodner ${ }^{2}$ \\ ${ }^{1}$ Center for Policy Research, The Maxwell School, Syracuse University, Syracuse, NY 13244- \\ 1020. \\ ${ }^{2}$ Research Associate, Center for Policy Research, The Maxwell School, Syracuse University, \\ Syracuse, NY 13244-1020.
}

\begin{abstract}
The purpose of this study is to update the results first presented in 1995 in the OECD Monograph, "Income Distribution in OECD Countries: Evidence from the Luxembourg Income Study" by Atkinson, Rainwater, and Smeeding (1995). Though only five years have passed since the publication of this volume, we are now able to compare the level of disposable income inequality across 20 nations, including Germany, in three separate periods using LIS. Moreover, we are now able to use several sets of national data to assess the changes in inequality that have taken place in recent years. The brief results are that the ranking of nations by the level of inequality at a point in time are more or less the same regardless of the year of comparison from roughly 1980-1997. But large changes in the distribution of income have taken place within many nations, with most finding a higher level of inequality in the mid-to-late 1990s than in the 1980s, and with Western Germany being no exception. Inequality, however, has not risen in Denmark or in Canada over this period, while its rise has slowed in several nations. This suggests that rising economic inequality is not inevitable. Strategies for improving these estimates are also discussed.
\end{abstract}




\section{Introduction: Cross-National Studies of Income Distribution}

Increasingly the rich nations of the world face a common set of social and economic issues: the cost of population aging, a growing number of single parent families, the growing majority of two-earner families, increasing numbers of immigrants from poorer nations, and in particular, rising economic inequality generated by skill-based technological change, international trade and other factors. While these increases are not inevitable, and while public policy and labor market institutions can help forestall these trends, the facts of the matter are that income inequality continues to increase in the large majority of the world's rich nations (e.g., see Atkinson 1999, 2000; Freeman 2000; Gottschalk 1997; Gottschalk, Gustaffson, and Palmer 1997; Danziger and Reid 1999). All of these rich nations have also designed systems of social protection to shield their citizens against the risk of a fall in economic status due to unemployment, divorce, disability, retirement, and death of a spouse. The interaction of economic and demographic forces and social programs generates the distribution of disposable income in each of these nations.

The recent evidence on the level and trend in economic and social inequality is the subject of this brief paper. The emergence and availability of cross-nationally comparable databases has put us in a position to directly compare the experiences of rich nations in coping with the growth of market income inequality.

The Luxembourg Income Study (LIS) project has pioneered the availability of online data which allows researchers to use microdata to measure inequality and to test their ideas and hypotheses about the sources and causes of that inequality using modern methods. In 1995 a LIS team published a benchmark OECD report on the differences in economic inequality across 
nations at a point in time (Atkinson, Rainwater, and Smeeding 1995). Some of these figures were subsequently updated by LIS researchers (e.g., Gottschalk and Smeeding 1997, 1999). The purpose of this paper is to briefly update the facts and figures in these reports by presenting evidence on the level and trend in income inequality as portrayed by the LIS data, and from other sources. We begin with a brief review of methodology. Then we turn briefly to the results for level of inequality. Trends in inequality come next and they are often more difficult to precisely assess than are levels, whether using LIS or other sources. The reasons why are briefly discussed before turning to a few suggestions results.

Comparisons of these experiences may help us to understand how one nation is similar to and different from other nations. It may also help us trace these differences to their economic demographic, and policy-related sources. The institutions which emerge in nations to help mitigate the forces of market-driven economic inequality are also of interest. Cross-national research has taught us that every nation must design its own set of social and economic policies tempered by its institutions, values, culture, and politics. But it has also shown that we can learn important features of policy design by looking at other nations. This paper closes by suggesting a few places to begin to look for these answers.

\section{Measuring Economic Inequality: The Basics}

Here we briefly review the sources of our evidence and their strengths and weaknesses. There are currently no international standards for income distribution which parallel the international standards used for systems of national income accounts. ${ }^{1}$ Hence, researchers need

\footnotetext{
${ }^{1}$ However, the "Canberra Group" of National Statistical offices and organizations (including LIS, the World Bank, the United Nations and others) are currently at work at producing them (Canberra Group 1997, 1998, 1999).
} 
to decide what they want to measure and how far they can measure it on a comparable basis. The Luxembourg Income Study (LIS) which underlies much of this paper offers the reader many choices of perspective in terms of country, income measure, accounting unit, and time frame. But its relatively short time frame (1979-1997 for most nations, but 1968-1997 for five countries) and limited number of observation periods per country (three to five periods per country at present) currently limits its usefulness for studying longer term trends in income distribution. The purpose of this section of the paper is to explain the choices we have made in our use of LIS. The choices we and others have made to study longer term trends in income distribution are more fully discussed in Gottschalk and Smeeding (1997, 1999) and Atkinson, Rainwater, and Smeeding (1995).

Our attention is focused here on the distribution of disposable money income, that is income after direct taxes and including transfer payments. Several points should be noted about this choice:

- income rather than consumption is taken as the indicator of economic well-being. Wealth is ignored except to the extent that it is represented by cash interest, rent, and dividends;

- the definition of income falls considerably short of a comprehensive definition, typically excluding much of capital gains, imputed rents, home production, and most of income inkind (with the exception of near-cash benefits);

- No account is taken of indirect taxes or of the benefits from public spending (other than cash and near-cash transfers) such as those from health care, education, or most housing subsidies;

- the period of income measurement is in general the calendar year with income measured on an annual basis. ${ }^{2}$

\footnotetext{
${ }^{2}$ The United Kingdom data is the only exception to this rule as their Family Expenditure Survey (FES) uses a bi-weekly accounting period with rules for aggregating up to annual totals. In Germany, LIS has aggregated the monthly and quarterly data into annual income amounts.
} 
Thus, variables measured may be less than ideal and results may not be fully comparable across countries. For example, one country may help low-income families through money benefits (included in cash income), whereas another provides subsidized housing, child care, or education (which is not taken into account). While, a recent study (Smeeding et al., 1993) finds that the distribution of housing, education and health care benefits reinforces the general differences in income distribution for a subset of the western nations examined here, there is no guarantee that these relationships hold for alternative countries or methods of accounting (Gardiner et al. 1995). Still most studies show that countries which spend more for cash benefits tend to also spend more for noncash benefits. Because noncash benefits are more equally distributed than are cash benefits, levels of inequality within high noncash spending countries are lessened, but the same rank ordering of these countries with respect to inequality levels that is found here using cash alone, persists when noncash benefits are added in. And while we use income, not consumption as the basis for our comparisons, due to the relative ease of measurement and comparability of the former, there is evidence that consumption inequalities are similar to income inequalities in major European nations and in the United States (deVos and Zaidi 1996; Johnson and Smeeding 1997).

The distribution of disposable income requires answers to both the "what" and the "among whom" questions. Regarding the former, earned income from wages and salaries and selfemployment, cash property income (but not capital gains or losses) and other private cash income transfers (occupational pensions, alimony, and child support) or "market income," is the primary source of disposable income for most families. To reach the disposable income concept used in this paper, governments add public transfer payments (social retirement, family 
allowances, unemployment compensation, welfare benefits) and deduct personal income tax and social security contributions from market income. Near-cash benefits- those which are virtually equivalent to cash (food stamps in the United States and housing allowances in the United Kingdom and Sweden) are also included in the disposable income measure used here.

The question of distribution "among whom" is answered among individuals. When assessing disposable income inequality, however, the unit of aggregation is the household: the incomes of all household members are aggregated and then divided by an equivalence scale to arrive at individual equivalent income. The equivalence scale used in the square root of household size and all LIS-based income measures in this paper use this equivalence scale and the "adjusted disposable income" concept which is produced by dividing (unadjusted) disposable income by family size raised to the power .5 (square root of family size). This is the same scale used in Atkinson, Rainwater, and Smeeding (1995) (see also, Buhmann, Rainwater, Schmaus, and Smeeding 1988).

For the most part, the household—all persons sharing the same housing unit regardless of familial relationship — is the common unit of analysis. However, for Sweden and Canada more restrictive nuclear family (Sweden) and economic family (Canada) definitions of the accounting unit are necessary (see Atkinson, Rainwater, Smeeding, 1995, Chapter 2, for additional details).

Complete intrahousehold income sharing is assumed, despite the fact that members of the same household probably do not equally share in all household resources. To assume that unrelated individuals living with others do not at all share in common household incomes or household "public goods" (heat, durables, etc.) is a worse assumption in our judgment. Thus, our unit of account is the household. 
The approach adopted here, based in large part on data from the Luxembourg Income Study (LIS), overcomes some, but not all, of the problems of making comparisons across countries and across time that plagued earlier studies. Some problems, for example, the use of data from different types of sources, still remains. But all of the data are drawn from household income surveys, or their equivalent, and in no case is synthetic data used. One major advantage of LIS is the availability of micro-data. The aim of the LIS project has been to assemble a single database containing survey data from many countries that is as consistent as possible. Access to the micro-data means that it is possible to produce results on the same basis, starting from individual household records, and to test their sensitivity to alternative choices of units, definition, and other concepts. It is therefore possible to make any desired adjustment for household size. Aggregate adjustments, such as that from pre-tax (market income) to post-tax (disposable) income are not necessary, although in some cases imputations are necessary at the household level. The data all cover, at least in principle, the whole non-institutionalized population though the treatment of immigrants may differ across nations.. These data are supplemented here by data provided by one major nation not yet a member of LIS (Japan) where a national expert calculated income inequality measures with the consultation of the LIS staff (i.e., Ichikawa 1996). The rest of the calculations were made by the author and the LIS project team. Many of the results cited here are directly available from the LIS home page (www.lissy.ceps.lu).

While the aim of the LIS project is to increase the degree of cross-national comparability, complete cross-national comparability is not possible, even if we were to administer our own surveys in each nation. Comparability is a matter of degree, and all that one can hope for is to reach an acceptably high level. In economic and statistical terms, the data is noisy, but the ratio of signal to noise is reduced by LIS. Ultimately the reader must decide the acceptability of the 
evidence before them. To skeptics we can offer that most of the cross-national results provided here have been reviewed by a team of national experts—statisticians, social scientists, and policy analysts-prior to their publication by OECD and in other forums, and they have appeared in refereed journals. And, because the LIS data is ultimately available to the research community at zero economic cost, researchers are free to repeat these calculations themselves. ${ }^{3}$

\section{Level of Inequality}

The LIS data sets are used here to compare the distribution of disposable income in 21 nations around 1995 and in earlier periods where 1995 data is not yet available. We focus here on relative (Figure 1) income differences, not absolute income differences. ${ }^{4}$ As will be demonstrated, the relative inequality patterns found here correspond roughly to the results found in Atkinson, Rainwater, and Smeeding (1995), which use earlier years' LIS data in most cases. Our choice of inequality measures are four: the ratio of the income of the person at the bottom and top $10^{\text {th }}$ percentiles to the median, $\mathrm{P}_{10}$ and $\mathrm{P}_{90}$, respectively; the ratio of the income of the person at the $90^{\text {th }}$ percentile to the person at the $10^{\text {th }}$ percentile- the decile ratio- (a measure of "social distance"); and the gini coefficient.

\subsection{Relative Differences in Inequality across Nations}

We begin with a chart containing all four measures of inequality with nations ordered by the decile ratio from lowest to highest. At the bottom of Figure 1 we find in the United States a

\footnotetext{
${ }^{3}$ For a critique of data series on inequality which are constructed from "secondary" datasets without access to the original microdata or without detailed documentation of data sources, data quality, and survey descriptions, see Atkinson and Brandolini (1999).
}

${ }^{4}$ For more on absolute income differences, see Rainwater and Smeeding (1999) and Gottschalk and Smeeding (1999). 
low income person at the $10^{\text {th }}$ percentile in $1997\left(\mathrm{P}_{10}\right)$ has an income that is 38 percent of the median. A high income person at the $90^{\text {th }}$ percentile $\left(\mathrm{P}_{90}\right)$, in contrast, has 214 percent of the median. The United States decile ratio is 5.64 meaning the income of the typical high income person is more than 5.5 times the income of the typical low income person, even after we have adjusted for taxes, transfers, and family size. In contrast, the average low income person has 52 percent of the income of the middle person in the average country; the average rich person has 182 percent as much, and the decile ratio shows an average "social distance" between rich and poor of 3.6 times $\mathrm{P}_{10}$.

At the other end of the chart, a Swedish citizen at $\mathrm{P}_{10}$ has 60 percent of the median, the $\mathrm{P}_{90}$ is 156 and the decile ratio is 2.59 , less than one-half as large as the United States value. This evidence suggests that the range of inequality and of social distance between rich and poor in the rich nations of the world is rather large in the mid-1990s.

Countries in Figure 1 fall into clusters, with inequality the least in Scandinavia (Finland, Sweden, Denmark, Norway) and Northern Europe (Belgium, Denmark, Luxembourg). Here $\mathrm{P}_{10}$ 's average 58 percent of the median and decile ratios are less than 3 , ranging from 2.59 to 2.92 and the gini range is, .222 to .240 . Central Europe comes next (The Netherlands, Germany, Austria, Switzerland, and France) with decile ratios from 2.89 to 3.39 and ginis from .282 to .323 .5

Taiwan is an anomalous entry in the middle of the table, with a gini (.277) and decile ratio (3.36) in the middle European range. Canada appears next with a lower gini (.286) and decile ratio (3.90) than any other Anglo-Saxon nation and with less inequality than that which is found 
in Southern Europe. Spain, Israel, Japan, Australia, and Ireland come next with decile ratios from 3.96 to 4.22 and ginis .305 and .330 . Finally, Italy (4.68) and the English speaking countries of the United Kingdom (4.52), and the United States (5.54) come last with the highest levels of inequality and the greatest social differences. Ginis here are .346 and above.

The United States has the highest decile ratio due in large part to its low relative incomes at the bottom of the distribution. The closest ratios to their $\mathrm{P}_{10}$ value of 38 are the United Kingdom (46),Italy (43), Australia (45), Canada (46), and Japan (46). No other nation has a value below 50. At the top of the distribution incomes in the United States are also a bit different from those in other high inequality nations. The $\mathrm{P}_{90}$ of 214 is highest followed by Ireland and the United Kingdom (209), Israel (205), and Italy (201), with no others above 200.

While percentile ratios as measures of social distance have some obvious appeal (e.g., insensitivity to top coding, ease of understanding), they have the disadvantage of focusing on only a few points in the distribution and lack a normative basis. Figure 1 presents an alternative more commonly employed Lorenz-based summary measure of inequality, the gini coefficient. As we saw above, relying on this measure, country rankings change little. Inequality is still lowest in Scandinavia, then Central Europe, Southern Europe, Asia with the English speaking countries (except for Canada) having the highest inequality and the United States the highest among these. Canada is in fact, the one anomaly worth noting. By the mid-1990s Canadian inequality as measured by the gini is at .286 , below that of Germany and about the same as France and The Netherlands.

\footnotetext{
${ }^{5}$ The figures for Germany include West Germany only; the Eastern lander data are not included here. For more on Eastern Germany as well, see Frick, Buchel, Krause, and Wagner (1997).
} 
In sum, there is a wide range of inequality among rich nations. Measures of social distance and overall inequality indicate that the United States has the most unequal distribution of adjusted household income among all 21 countries covered in this study, while Sweden has the most equal. In terms of groupings, the Scandinavian and Benelux countries have the most equal distributions, Central Europe is in the middle of the groupings, and the United Kingdom and Italy coming closest to the degree of inequality found in the United States.

\subsection{Robustness of Rankings}

Eleven of the 20 nations in Figure 1 were included in the 1995 OECD report. There we presented data on inequality for the mid-1980s. Have the rankings of these same nations changed much, if at all, since then? Table 1 provides an answer by comparing the original rankings with two later sets of rankings for the same nations. Despite the fact that inequality rose from the mid-1980s to the mid-1990s by 5 percent or more in 7 of the 11 nations, the inequality groupings did not change very much. Scandinavia and Northern and Central Europe had less inequality than did the Anglo-Saxon nations, particularly the United States. Hence, even when there is a general trend toward greater economic inequality across nations, systematic differences across countries tend to persist over time. The only minor exception to this general rule seems to be in Canada where ranking did not change much but inequality is flat and moving closer to Northern European levels than to Anglo-Saxon or Italian levels.

\section{Trends in Inequality}

Do the differences in inequality in OECD countries in the late 1980s and early 1990s reflect convergence to a common level of inequality or are the less equal countries (the United States, the United Kingdom, and Australia) becoming even less equal? To answer these 
questions we compare recent trends in inequality (from 1979 onwards). Because the LIS data cover only two to four data points in each nation, we also rely on published and unpublished data from other sources to assess the trend in income inequality (Gottschalk and Smeeding 1997, 1999; Gottschalk, Gustafson, and Palmer 1997; OECD 1999; Atkinson and Brandolini 1999; Atkinson, Rainwater, and Smeeding 1995; Atkinson 2000).

While differences in units, income measures equivalence adjustments and other factors in different studies make it difficult to compare levels of inequality across these studies, trends in inequality will be comparable as long as income concepts, surveys (and their methodologies), and inequality measures remain constant within countries over time. Unfortunately, they do not always follow this rule. Hence, we first discuss a series of factors that should be taken into account when assessing the trend in income inequality within any single nation and across nations over time.

\subsection{Landmines and Mudslides: Measuring the Trend in Income Inequality Over Time}

Trend measurement of income inequality may be even more difficult than is measurement of the level of inequality. The lure of trend measurement is that even if the income concept differs across nations, "consistent" measurement of inequality within any nation over time is liable to provide a good estimate of the "true" trend in income inequality (Gottschalk and Smeeding 1999). However, the longer the time period, the less likely are we to find a consistent measure.

A sampling of the problems that may arise in assessing trends must include the following:

- Definitional differences in income. When some nations include items such as realized capital gains and others do not, both level and trend may be affected (e.g., Eriksson 1999), even if capital gains are measured the same over time in the same nation. The reason is, of course, the sensitivity of realized capital gains to business cycles and to tax 
practices. The trend in income inequality in Sweden is therefore sensitive to the definition of income employed. ${ }^{6}$

- Definitional differences in populations. The treatment of different population groups may affect income distribution trends if immigrants or other groups are excluded from the group for which one makes income calculations, at the same time that immigration is increasing. Germany provides one example of a nation where this may be true (Frick et al. 1997).

- Differences in survey collection practices. In both Sweden and the United States, early 1990s changes in data collection practices created discontinuous "breaks" in otherwise comparable longer series of inequality estimates.

- Periodicity and cyclicity may be important and may differ. If the period of measurement begins at a cyclical peak and ends at a trough (or median), there may be a business cycle bias to measured trends in inequality. Because business cycles differ across nations in a non-systematic way, using the same period data for each country does not guarantee that this bias is removed. Long data series can overcome such obstacles. However, data series based on two or three data points (e.g., those found in Spain and Portugal) may be sensitive to cyclical inferences.

In general, nations with multiple data series from different sources, and counties which clearly identify survey differences and changes in survey practices over time, provide the best sources of distributional trend comparisons. Nations with very few data points and those with not well identified survey practices or concepts do not always provide accurate sources for trend analysis. Decisions about which nations to include and exclude based on data quality considerations should be at the forefront of the users agenda.

Moreover, the magnitude of some problems can change from time-to-time and we must remain vigilant to capture these differences. For example, many nations "top" or "bottom" code survey incomes to maintain confidentiality for respondents when releasing the data for "public"

\footnotetext{
${ }^{6}$ For instance, the Swedish series produced by their Central Statistical Office shown in Table 3 and used in Erikson (1999) and Gottschalk and Smeeding (1999), finds that inequality rises from the mid-1980s through the mid-1990s. The LIS income definition and data show no such trend (see Table 1).
} 
(research) users. Nations differ in their methodologies for limiting levels of income at either end of the distribution, top or bottom. In earlier work (Smeeding 1996; Atkinson, Rainwater, and Smeeding 1995), this was not an important issue. Hence, topcoding of survey data at some multiple of the median (e.g., ten times) and bottom coding at some fraction of disposable income (e.g., 1 percent of the mean level) as is the LIS practice did not create large problems for crossnational comparisons of level or trend in inequality.

The rapid growth of high incomes in the United States during the 1990s provides a good example of the sensitivity of ginis and lack of sensitivity of decile ratios to topcoding. In 1995 the U.S. Census Bureau raised the highest reported cash income public use file (LIS file) topcode from $\$ 100,000$ to $\$ 150,000$. Further, they averaged all reported incomes above that level and gave each household with incomes above $\$ 150,000$ the average income for this group. Alternatively, they could have left the topcode at $\$ 100,000$ as it was before that date, or they could have raised the topcode to $\$ 150,000$ alone. Table 2 presents the effects of these changes. The 1997 decile ratio does not change under any of the procedures and for the first time since the late 1970s, the decile ratio shows a decline compared to the early 1990s. We suspect that the effects of tax subsidies for the poor and more progressive taxes on the rich since 1994 likely contributed to the increases in $\mathrm{P}_{10}$ and decreases in $\mathrm{P}_{90}$ which reduced the decile ratio. However, changes in the gini coefficient show a continued trend toward greater inequality, and the trend is sensitive to the topcode. If LIS enforced the topcode at $\$ 100,000$ to be consistent with earlier years, the gini would rise by about 5 percent or to 0.359 from 1991 to 1997 (or roughly the same from 1994). If we follow the current procedure and topcode at $\$ 150,000$ plus the mean of all incomes above, the gini rises to 0.375 in 1997 or by a full 10 percent over 1991 . The $\$ 150,000$ 
topcode provides an intermediate estimate. Because the new topcoding procedure produces an above $\$ 150,000$ income which is less than ten times the LIS median level (of about $\$ 30,000$ ) the LIS uniform topcoding rule produces the same 0.375 estimate as is found in Figure 1 . However, the gini inequality measure and the trend in inequality within the United States is clearly sensitive to how the data is topcoded.

Many of these issues have been raised by others (e.g., Atkinson and Brandolini 1999; Gottschalk and Smeeding 1999; Atkinson, Rainwater, and Smeeding 1995), so we do not delve deeper into them here. A forthcoming paper for the Canberra group will more thoroughly address these issues (Atkinson, Brandolini, van der Laan, and Smeeding 2000).

Given these differences we should go slowly and carefully when assessing trends in economic inequality across and within nations. Earlier we wrote that in the case of LIS-based cross-sectional estimates of the comparably defined level of economic inequality, many of the "landmines" of inequality measurement were uncovered (Atkinson, Rainwater, and Smeeding 1995). However, in the case of trend analyses many of these mines are just beginning to emerge. Hence, we must be continuously aware of the difficulties of measuring true longer term trends in equality, as compared to data-driven, method-driven, or period-driven "mudslides" in many national data series. With this warning we very cautiously proceed.

\subsection{LIS Trend Data}

Because we have been collecting LIS data for over 15 years now, we are able to use LIS data to investigate trends in income inequality using the LIS datasets. The reader should be warned that LIS does its best to guarantee differences in inequality measurement at a point in time, and is less well suited for measuring changes in inequality over time. For most nations, LIS has few datapoints. Moreover, in choosing the best data for comparisons at a point in time, 
different surveys are used in different nations. For instance, in Germany, three different datasets have been used by LIS and these three do not lend themselves easily to trend analyses. Even though LIS is careful to note when different datasets, income definitions, or other changes take place in national datasets, the availability of data alone does not guarantee its consistency over time. Over these 15 years of normalizing microdata to a common definition, many of the cautions urged above have been learned from trying to assess inequality trends using LIS. Survey practices and data quality have differed over these 15 years in most of the countries found in Figure 2. In some cases a new survey replaces the old (e.g., Australia 1994). In others, panel datasets (Luxembourg, Germany) which provide the LIS cross-sections have suffered from sample attrition and have not added new immigrants to their original samples for LIS. Finally, many nations provide income distribution trend data based on national definitions of income which include income items not included in LIS income such as capital gains (Sweden), and imputed rent (The Netherlands), while several others typically exclude nearcash income. Finally, the weighted sum total of aggregate incomes taken from the surveys in several countries may be substantially below somewhat comparable aggregate national incomes suggesting that income underreporting may be a serious issue (e.g., Italy, Spain).

Despite these differences, the LIS data provide some information on the trend in economic inequality (Figure 2). These data indicate that inequality has risen in most LIS nations from the mid-1980s to the mid-1990s: dramatically in the United States, the United Kingdom, and in Italy; less dramatically but still a rise in Germany, Australia, and The Netherlands; a very slight increase in Sweden, Finland, and Norway; and no change in Luxembourg and Canada. While these changes may be reasonable, they should be compared to those from other sources which are designed to produce more accurate trend data. 


\subsection{National Trend Data}

The data on trends in income inequality has grown dramatically in recent years. When the Atkinson, Rainwater, and Smeeding (1995) report was published, there was evidence that among 16 countries observed during the 1980s, eight of these nations experienced an increase in inequality, six no change (where a one to two percentage points was taken as a change) and two (Italy and Portugal) showed a decrease in inequality. These results are shown in the first 15 rows of Table 3, along with similar summaries of other national trends based on data collected since the OECD report and for periods before and after the 1980s which the OECD report focused upon. Countries for which we had only two datapoints (e.g., Spain and Portugal) are not counted here. $^{7}$

The results in Table 3 present an impressionistic summary. The objective of the table is to give a general summary. To date, no one has spent the time, effort, and hard work necessary to fully and completely assess the level and change in the quality of data; the treatment of survey differences; gini series breaks; top and bottom coding; definitional differences; population differences (immigrants); and all of the other problematic aspects which are needed for a thorough analysis of the topic for all of these nations. For many countries, the data series are robust and well documented. In many nations, several series of data point to the same general conclusion. But the documentation is uneven and could be improved upon. At this point, the author puts enough confidence in these series to present them in this form.

The following impressions can be gleaned from the table:

\footnotetext{
${ }^{7}$ Portugal, for which we have only two datapoints, has been excluded from Table 3, but was one of the 16 countries summarized in Atkinson, Rainwater, and Smeeding (1999).
} 
- The OECD study focused on the 1980s which were a period of transition from one period (flat or declining inequality) to another period (rising inequality) in most nations. This best describes a "U"-shaped change in the distributions of income in most nations with inequality falling in the 1960s (few comparable observations), and early 1970s, but then rising from the late 1970s and 1980s into the 1990s. The turning points (bottom of the U) differ across nations. Many (e.g., the Scandinavian nations) did not experience a rise in inequality until the 1990s. And in many nations (e.g., Germany, France) these increases were fairly modest.

- At least two nations, Canada and Denmark, are clearly against the trend. Inequality has declined in Denmark from the mid-1980s and has been flat in Canada since the late 1970s through 1996. We need to know more about both of these anomalies, particularly about Canada (Atkinson 2000).

- While inequality rose rapidly in the United Kingdom and the United States during the 1980s and early 1990s, the trend seems to have flattened out in both countries. To the extent that the United Kingdom income distribution source (Family Expenditure Survey) and United States source (Current Population Survey) do not accurately capture or measure incomes in high income households (due to topcoding, nonresponse, etc.), this conclusion may be unwarranted (see Table 2). However, the rate of increase in inequality has at least slowed in these nations in the late 1990s.

\subsection{Summary}

It appears that the quality and quantity of consistent and good quality information on income distribution trends is somewhat lacking. Recent work by Atkinson (2000), Atkinson and Brandolini (1999), and the OECD (1999) in conjunction with LIS has made some headway into the issue, but much needs to be done. The Canberra Group (1999) is also assessing these issues and forging a set of guidelines for future production of more consistent and comparable measures of income inequality. To the extent that these data emerge, we will be in a better position to model changes in inequality and to understand its evolution.

As Atkinson (2000) concludes rising economic inequality is not inevitable—Canada and Denmark seem to present at least two exceptions to the rule. However, rising income inequality is predominant. And while inequality has increased, our reading of the LIS data, and to a lesser extent the international trend data, suggest that there have been different patterns of the timing 
and extent of the increase in inequality in most nations. Moreover, national changes in inequality may have different welfare implications depending on whose income inequality is changing. In the United States, for instance, the $\mathrm{P}_{10}$ is finally moving upwards. In Sweden, Germany, Norway, and Finland, most of the higher inequality in the 1990s seems to be coming from movements at the top of the distribution (from changes in $\mathrm{P}_{90}$ 's) not from changes in the bottom (e.g., $\mathrm{P}_{10}$ 's) (Gottschalk and Smeeding 1999). Only a few authors (e.g., Gustafsson and

Johanssen 1998; Osberg 2000), have begun to sort out the sources of differences in inequality levels and trends. Much additional work is needed here.

\section{Summary and Conclusions}

This brief paper has perhaps asked more questions than it has given answers. This is how the paper was meant to be written. Understandings and explanations of the broad structures of economic inequality within and across nations and over time depend heavily on the quality of the data which we have at our disposal. For social scientists interested in this topic, economic inequality data is equivalent to the astronomer's Hubbell telescope or the geneticist's Human Genome project. Without accurate indicators, model building and hypothesis testing cannot adequately proceed. Cross-national data on income distribution will never be perfect. The ratio of signal to voice in these data can, however, can still be improved, as the LIS project has demonstrated.

If we believe in the pictures of inequality levels drawn by the LIS, we can see that there is a systematic structure to point in time estimates of inequality across nations. Most data on trends in inequality are less clear and in need of quality improvement, robustness assessments, and further verification. However, the somewhat fuzzy picture that they paint is fascinating. If we 
are to assess the importance of economic conditions, institutions, and policies as they affect inequality or as they are affected by inequality, it behooves us all to follow the lead of the Canberra Group $(1997,1998,1999)$ and to work hard to improve our basic indicators of income inequality and to make them more comparable across nations and over time. 


\section{Acknowledgements}

The authors would like to thank the LIS country sponsors, the Ford Foundation, and the MacArthur Network on Family and the Economy for their support of this research, and Anthony B. Atkinson, Andrea Brandolini, Richard Hauser, and Irene Becker for comments on an earlier draft. Kati Foley, Paul Alkemade, and Esther Gray provided excellent assistance with manuscript and figure preparation. However, the authors are responsible for any remaining errors of commission or omission. 


\section{References}

Atkinson, A.B. 2000. "Is Rising Income Inequality Inevitable? A Critique of the Transatlantic Consensus," WIDER Annual Lecture \#3. Helsinki, Japan: United Nations World Institute for Development Economics Research, mimeo.

Atkinson, A.B., A. Brandolini, P. van der Laan, and T.M. Smeeding. 2000. "Measuring the Trend in Income Inequality." To be presented tot he Canberra Group, Differdange Luxembourg, May 16, 2000.

Atkinson, A.B. and A. Brandolini. 1999. "Promises and Pitfalls in the Use of 'Secondary' DataSets: Income Inequality in OECD Countries," mimeo. Oxford, UK: Nuffield College, July.

Atkinson, A.B., L. Rainwater, and T.M. Smeeding. 1995. Income Distribution in OECD Countries: Evidence from the Luxembourg Income Study (LIS). Paris: OECD.

Buhmann, B., L. Rainwater, G. Schmaus, and T.M. Smeeding. 1988. "Equivalence Scales, Well-Being, Inequality, and Poverty: Sensitivity Estimates Across Ten Countries Using the Luxembourg Income Study (LIS) Database," Review of Income and Wealth (June): 115-142.

Canberra Group. 1999. Third Meeting on Household Income Statistics: Papers and Final Report. Ottawa, Canada: Statistics Canada, August.

Canberra Group. 1998. Papers and Final Report of Second Meeting on Household Income Statistics. Amsterdam, The Netherlands: Statistics Netherlands, Voorberg/Heirlen, May.

Canberra Group. 1997. Papers and Final Report: First Meeting on Household Income Statistics. Canberra, Australia: Australian Bureau of Statistics, February.

Danziger, S. and D. Reed. 1999. "Winners and Losers: The Era of Inequality Continues," Brookings Review (Fall): 14-17.

DeVos, K. and A. Zaidi. 1996. "Inequality in Consumption vs. Inequality of Income in the EC," mimeo. The Netherlands: University of Leiden.

Erikson, I. 1999. "Income Distribution Trends in Sweden." Stockholm, Sweden: Swedish Ministry of France, July.

Freeman, R. 2000. "Single Peaked vs. Diversified Capitalism: The Relation between Economic Institutions and Outcomes," NBER Working Paper \#7556. Cambridge, MA: National Bureau of Economic Research, February.

Frick, J., F. Buchel, P. Krause, and G. Wagner. 1997. "Immigration Has Increased Inequality and Poverty in Germany Slightly," Economic Bulletin, 34(2): 25-32.

Gardiner, W., J. Hills, J. Falkingham, H. Sutherland, and V. Lechene. 1995. "The Effects of Differences in Housing and Health Care Systems on International Comparisons of Income Distribution," Welfare State Programme Discussion Paper No. 100, STICERD, London School of Economics.

Gottschalk, P. 1997. "Inequality, Income Growth and Mobility: The Basic Facts," Journal of Economic Perspectives (summer).

Gottschalk, P., B. Gustaffson, and E. Palmer (eds.). 1997. The Distribution of Economic Welfare in the 1980s: An Economic Perspective. Cambridge: Cambridge University Press.

Gottschalk, P. and T.M. Smeeding. 1999. "Empirical Evidence on Income Inequality in Industrialized Countries." In A.B. Atkinson and F. Bourgignon (eds.), Handbook of Income Distribution. New York: Elsevier-North Holland Publishers. 
Gottschalk, P. and T.M. Smeeding. 1997. "Cross-National Comparisons of Earnings and Income Inequality," Journal of Economic Literature, XXXV (June): 633-687.

Gustafsson, B. and M. Johansson. 1997. "In Search for a Smoking Gun: What Makes Income Inequality Vary Over Time in Different Countries?" LIS Working Paper \#172, Luxembourg Income Study. Syracuse, NY: Syracuse University, November.

Ishikawa, Tsuneo. 1996. Data runs conducted by the Ministry of Welfare, Japan, November 26.

Johnson, D. and T. Smeeding. 1997. "Measuring the Trends in Inequality of Individuals and Families: Income and Consumption." Paper presented to the American Economic Association. January 6.

Organisation for Economic Co-operation and Development (OECD). 1999. "Trends in Income Distribution and Poverty in the OECD Area," Social Policy Studies No. 1. Paris: OECD, September 21.

Osberg, L. 2000. "Long Run Trends in Economic Inequality in Five Countries-A Birth Cohort View," LIS Working Paper No. 222. Luxembourg: Luxembourg Income Study.

Rainwater, L. and T.M. Smeeding. 1999. "From 'Relative' to 'Real' Income: Purchase Power Parities and Household Income Microdata, Problems and Prospects." In M. Sheridan, L. Rouillard, and A. Choquette (eds.), Third Meeting on Household Income Statistics: Papers and Final Report. Ottawa, Canada: Statistics Canada (June): 139-163.

Smeeding, T.M. 1997. "U.S. Income Inequality in a Cross-National Perspective: Why are We So Different?" Looking Ahead, XIX(2-3): 41-50. Reprinted in J. Auerbach and R. Belous (eds.), The Inequality Paradox: Growth of Income Disparity. Washington, DC: National Policy Association, pp. 194-217.

Smeeding, T.M. 1996. “America's Income Inequality: Where Do We Stand?" Challenge (September/October): 45-53.

Smeeding, T.M., P. Saunders, J. Coder, S. Jenkins, J. Fontall, A. Hagenaars, R. Hauser, and M. Wolfson.. 1993. "Poverty, Inequality and Family Living Standards Impacts Across Seven Nations: The Effect of Noncash Subsidies for Health, Education and Housing," Review of Income and Wealth, 39(3) (September): 229-256. 
Table 1. Ranking of OECD countries by Ginis of the first wave vs. other waves of LIS data

\begin{tabular}{|c|c|c|c|c|c|c|c|c|c|c|}
\hline $\begin{array}{c}\text { 1st wave } \\
\text { rank }\end{array}$ & Country & year $^{1}$ & Gini & $\begin{array}{c}\text { 2nd wave } \\
\text { rank }\end{array}$ & year $^{1}$ & Gini & $\begin{array}{c}\text { 3rd wave } \\
\text { rank }\end{array}$ & year $^{1}$ & Gini & change $^{2}$ \\
\hline 1 & Finland & 1987 & 0.207 & 1 & 1991 & 0.223 & 2 & 1995 & 0.226 & + \\
\hline 2 & Sweden & 1987 & 0.220 & 2 & 1992 & 0.229 & 1 & 1995 & 0.222 & 0 \\
\hline 3 & Norway & 1986 & 0.234 & 3 & 1991 & 0.234 & 4 & 1995 & 0.242 & 0 \\
\hline 4 & Luxembourg & 1985 & 0.238 & 4 & 1991 & 0.239 & 3 & 1994 & 0.235 & 0 \\
\hline 5 & Germany & 1984 & 0.265 & 6 & 1989 & $0.281^{3}$ & 7 & 1994 & 0.300 & + \\
\hline 6 & Netherlands & 1987 & 0.268 & 5 & 1991 & 0.272 & 5 & 1994 & 0.282 & + \\
\hline 7 & Canada & 1987 & 0.289 & 7 & 1991 & 0.286 & 6 & 1994 & 0.286 & 0 \\
\hline 8 & Australia & 1985 & 0.295 & 9 & 1989 & 0.310 & 8 & 1994 & 0.317 & + \\
\hline 9 & United Kingdom & 1986 & 0.304 & 10 & 1991 & 0.340 & 9 & 1995 & 0.346 & + \\
\hline 10 & Italy & 1986 & 0.310 & 8 & 1991 & 0.290 & 9 & 1995 & 0.346 & + \\
\hline 11 & United States & 1986 & 0.341 & 11 & 1991 & 0.342 & 11 & 1997 & 0.375 & + \\
\hline Notes: & $\begin{array}{l}{ }^{1} \text { Atkinson, Rair } \\
2+\text { means sign } \\
{ }^{3} \text { Preliminary es }\end{array}$ & r, Sme & (1995) & ole 4.1. & s 19 & 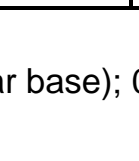 & 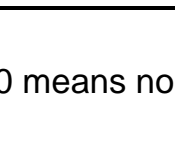 & 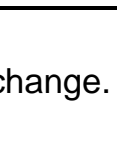 & & \\
\hline Source: & Luxe & udy & & & & & & & & \\
\hline
\end{tabular}


Table 2

Trends in United States Income Inequality using LIS Data

\begin{tabular}{crrrr}
\hline Year & P10 & P90 & P90/P10 & Gini \\
\hline 1991 & 34 & 208 & 6.118 & 0.341 \\
1994 & 36 & 219 & 6.083 & 0.342 \\
$1997^{\mathrm{a}}$ & 38 & 214 & 5.632 & 0.375 \\
$1997^{\mathrm{b}}$ & 38 & 214 & 5.643 & 0.359 \\
$1997^{\mathrm{C}}$ & 38 & 214 & 5.643 & 0.370 \\
\hline
\end{tabular}

Notes:

a top coded at $\$ 150,000$ with the mean income above this level assigned to all households with higher incomes.

${ }^{b}$ top coded at $\$ 100,000$ of income in 1997 as in 1991 and 1994.

${ }^{c}$ top coded at $\$ 150,000$ of income in 1997 with no income above that level. 
Table 3. Overall Trends in Income Distribution: Summary Results from National and Cross-national Studies

\begin{tabular}{|c|c|c|c|}
\hline & $\begin{array}{l}\text { Mid/Early } 1970 \text { s } \\
\text { to } \\
\text { Mid/Late } 1980 s^{1}\end{array}$ & $\begin{array}{c}\text { OECD Study } \\
1980 \text { s } \\
\left(\text { ) = } \text { other estimate }^{2}\right.\end{array}$ & $\begin{array}{c}\text { Mid/Late } 1980 \mathrm{~s} \\
\text { to } \\
\text { Mid/Late } 1990 \mathrm{~s}^{3}\end{array}$ \\
\hline Australia & 0 & + & + \\
\hline Austria & 0 & 0 & ++ \\
\hline Belgium & 0 & + & + \\
\hline Canada & - & 0 & 0 \\
\hline Finland & - & 0 & + \\
\hline France & - & $0(-)$ & + \\
\hline Germany & - & + & + \\
\hline Ireland & - & 0 & + \\
\hline Italy & - & - & ++ \\
\hline Japan & 0 & + & + \\
\hline Netherlands & 0 & + & ++ \\
\hline Norway & 0 & 0 & ++ \\
\hline Sweden & - & + & + \\
\hline United Kingdom & ++ & +++ & ++ \\
\hline United States & ++ & ++ & ++ \\
\hline Denmark & na & na & - \\
\hline New Zealand & 0 & $\mathrm{na}(+)$ & +++ \\
\hline Switzerland & na & na & + \\
\hline
\end{tabular}

$\begin{array}{cl}+++ & \text { Significant rise in income inequality (more than } 15 \text { percent increase) } \\ ++ & \text { Rise in income inequality ( } 7 \text { to } 15 \text { percent increase) } \\ + & \text { Modest rise in income inequality }(1 \text { to percent increase) } \\ 0 & \text { No change }(-1 \text { to }+1 \text { percent change) } \\ - & \text { Modest decrease in income inequality }(1 \text { to } 7 \text { percent decrease) } \\ -- & \text { Decrease in income inequality ( } 7 \text { to } 15 \text { percent decrease) } \\ -- & \text { Significant decrease in income inequality (more than } 15 \text { percent decrease) } \\ \text { na } & \text { No consistent estimate available. }\end{array}$

General Note: The results are based on several income inequality indicators in most countries and reflect the general trends reported in national and comparative studies. However, trends are always sensitive to beginning and ending points as well as to other cautions mentioned in the text.

Sources and Notes: OECD (1998); ${ }^{1}$ Atkinson, Rainwater and Smeeding (1995); OECD (1999); Gottschalk and Smeeding $(1997,1999){ }^{2}$ Atkinson, Rainwater and Smeeding (1995) for all but parenthesis which come from alternative sources listed in these references; ${ }^{3}$ Atkinson and Brandolini (1999); Gottschalk and Smeeding (1999); Atkinson (2000); OECD (1999); and Luxembourg Income Study. 
Figure 1. Decile Ratios and Gini Coefficient for Adjusted Disposable Income

(numbers given are percent of median in each nation and Gini coefficient)

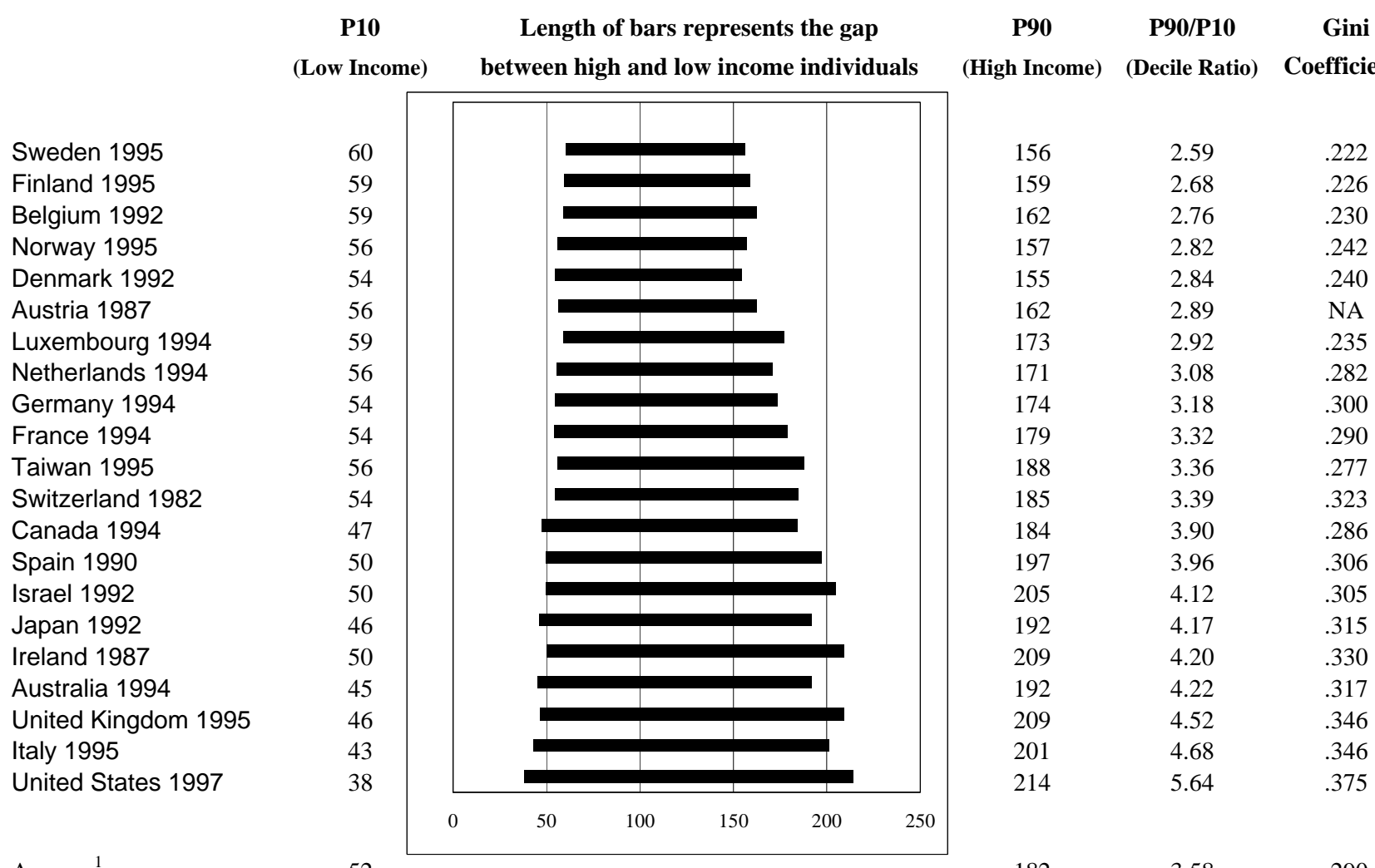

Average $^{1}$

52

182

.290

Source: Author's calculations from Luxembourg Income Study.

${ }^{1}$ Simple average.

${ }^{2}$ Gini coefficients are based on incomes which are bottom coded at 1 percent of disposable income and top coded at 10 times the median disposable income. 
Figure 2. Trends and Levels of Gini Coefficient in OECD Countries (LIS).

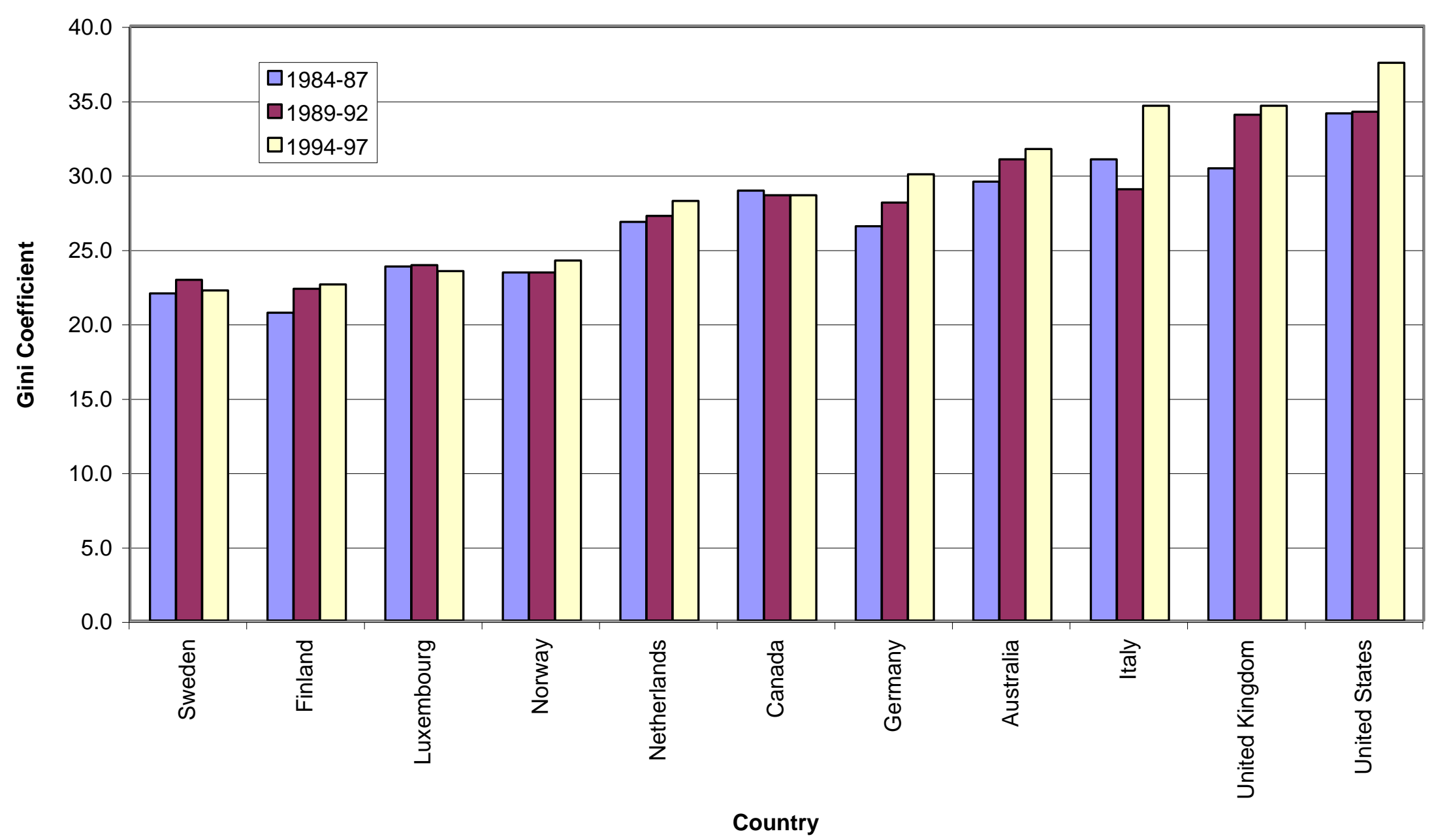

Source: Author's calculations from Luxembourg Income Study. See Table 1. 